\title{
Two-port access versus four-port access laparoscopic ovarian cystectomy
}

\author{
Won-Kyu Choi, Jang-Kew Kim, Jung-Bo Yang, Young-Bok Ko, Sang-Lyun Nam, Ki-Hwan Lee \\ Department of Obstetrics and Gynecology, Chungnam National University School of Medicine, Daejeon, Korea
}

\section{Objective}

This study was conducted to compare the surgical outcomes between two-port access and four-port access laparoscopic ovarian cystectomy.

\section{Methods}

Four hundred and eighty nine patients who had received two-port access laparoscopic ovarian cystectomy ( $n=175)$ and four-port access laparoscopic ovarian cystectomy $(n=314)$ in Chungnam National University Hospital from January 2009 to August 2012 were analyzed retrospectively. The data were compared between the bilaterality of the cysts and cyst diameter of less than $6 \mathrm{~cm}$ and $6 \mathrm{~cm}$ or more.

\section{Results}

There were no significant differences in patient's age, parity, body weight, body mass index and history of previous surgery between the two-port and four-port access laparoscopy group. Bilaterality of ovarian cysts was more in fourport access laparoscopy group $(13.7 \%$ vs. $32.5 \%, P=0.000)$. There were no significant differences in operation time, hemoglobin change, hospital stay, adhesiolysis, transfusion, and insertion of hemo-vac between the two-port and four-port access laparoscopy group for size matched compare. However additional analgesics were more in four-port access laparoscopy group for unilateral ovarian cystectomy.

\section{Conclusion}

Two-port access laparoscopic surgery was feasible and safe for unilateral and bilateral ovarian cystectomy compare with four-port access laparoscopic surgery.

Keywords: Cystectomy; Ovarian cysts; Two-port access laparoscopy

\section{Introduction}

One of the most common disease that occur in women of childbearing age is benign ovarian cysts. In the young woman, ovarian cystectomy underwent surgery rather than salpingooophorectomy if possible, as an important key to the preservation of ovarian function [1].

Laparoscopic surgery as compared to open surgery is performed because of reduction of pain after surgery, the short length of hospital stay, reduction of postoperative intraabdominal adhesions, various advantages such as a cosmetic effect [2]. In the past, the classical laparoscopic surgery was used the four ports, but recently becoming a change to tend to minimize the number of port, such as single-port access laparoscopic ovarian cystectomy or two-ports access laparoscopic surgery in order to maximize the advantages of the laparoscopic surgery [3]. Two-ports access laparoscopic surgery has some advantages such as small number of operation wound and cosmetic effect. However, technically more difficult than four-ports access laparoscopic surgery.

Received: 2013.3.6. Revised: 2013.7.30. Accepted: 2013.9.16. Corresponding author: Ki-Hwan Lee

Department of Obstetrics and Gynecology, Chungnam National University Hospital, 282 Munhwa-ro, Jung-gu, Daejeon 301-721, Korea Tel: +82-42-280-7260 Fax: +82-42-280-7264

E-mail: oldfox@cnuh.co.kr

Articles published in Obstet Gynecol Sci are open-access, distributed under the terms of the Creative Commons Attribution Non-Commercial License (http://creativecommons. org/licenses/by-nc/3.0/) which permits unrestricted non-commercial use, distribution, and reproduction in any medium, provided the original work is properly cited.

Copyright $\odot 2014$ Korean Society of Obstetrics and Gynecology 


\title{
Obstetrics \& Gynecology Science
}

\author{
Vol. 57, No. 5, 2014
}

This study is comparing the two-ports access laparoscopic surgery and four-ports access laparoscopic surgery in patients who underwent laparoscopic ovarian cystectomy with benign ovarian cyst attempt to investigate whether there were differences in the clinical course such as hospitalization, amount of bleeding, surgery time, and pain.

\section{Materials and methods}

\section{Materials}

Three years and eight months from January 2009 to August 2012, we analyzed retrospective study. Four hundred eightynine patients who underwent laparoscopic ovarian cystectomy due to benign ovarian cyst were in Chungnam National University Hospital. Patients was limited to the cases received surgery to laparoscopic surgery over 6 years specialist experience. One hundred seventy-five patients were underwent two-ports access laparoscopic surgery and 314 patients were underwent four-ports access laparoscopic surgery. Until February 2011 we performed four-ports access laparoscopic surgery, after March 2011 we performed two-ports access laparoscopic surgery. There was a no conversion to open surgery during laparoscopic surgery.

Age, parity, weight, body mass index, history of surgery, ultrasound examination of the ovarian cyst measuring the maximum diameter and whether bilateral, whether adhesions, tissue characteristics, operative time, perioperative hemoglobin levels changes, transfusion status, additional analgesics due to postoperative pain, postoperative hospital stay were investigated by examining the medical records of patients.

Surgical history was determined by the number of laparotomy (open surgery) and laparoscopic surgery. Hemoglobin level was calculated as the difference between the measured value of the second day after surgery and preoperative hemoglobin level. We checked adhesiolysis and other operation during the ovarian cystectomy and operation time was measured from incision to skin closure.

\section{Methods}

Prophylactic antibiotics were administered before surgery. With general anesthesia and the Trendelenburg position, the abdomen and thighs were disinfected with povidone. After covering the surgical drape, $18 \mathrm{~F}$ foley catheter was inserted into the bladder. If patients has coital history, we were in- serted Uterine Manipulator (Zinnanti Uterine Manipulator Injector, CooperSurgical Inc., Trumbull, CT, USA). The surgery was taken Trendelenburg positions that lowers the head 300 about the patient. For endometriosis, surgery was performed ovarian cystectomy and adhesiolysis and pelvic cavity endometrial tissue excision. Postoperative drainage tube was inserted only if there is high risk of bleeding. After removing ovarian cysts, ovaries are not sutured. The ovarian cystectomy site was covered with Interceed (Ethicon Endo-Surgery, Cincinnati, $\mathrm{OH}$, USA) to prevent adhesion. The peritoneum and fascia were sutured with 2-0 Vicryl, skin was sutured with 2-0 Nylon.

As a default, all patients were applied patient controlled analgesia (PCA) for pain control. PCA was used as a mixture of $45 \mathrm{mg}$ of morphine and ketoracin $120 \mathrm{mg}$ of $5 \%$ glucose solution $100 \mathrm{~mL}$. Administration rate was $2 \mathrm{~mL}$ per hour and lasted about two days. If patients press the button $2 \mathrm{~mL}$ PCA was applied to be administered. Visual analog scale score if this was more than 5 points were muscular diclofenac injected. If patients had a fever or non-steroidal anti-inflammatory drugs adverse effects, pethidine was injected $25 \mathrm{mg}$ on intramuscular.

\section{1) Two-ports access laparoscopic ovarian cystectomy}

One-centimeter incision in the umbilicus and $\mathrm{CO}_{2}$ filled by inserting a Verres needle. Ten-millimeter trocar was inserted and pelvic status and disease were confirmed by pelviscope. Ten-millimeter trocar was removed and the incision in the umbilicus was expanded to $2 \mathrm{~cm}$ then secured with surgical pathway by Octoport (Octo-Port, DalimSurgNet, Seoul, Korea) or Alexis wound protractor (Applied Medical, Rancho Santa Margarita, CA, USA) and a glove. Surgical pathway made by a wound retractor and a glove and finger cut with scissors three places out of surgical gloves inserted two 5-mm ports, one 10-mm port and then tied with a rubber band is not leaking gas. Surgery was performed after additional insertion one 5-mm port in the left lower abdomen and used a 30-degreeangle, 5-mm-diameter, 43-cm-length pelviscope.

Surgeon was standing on the left side of patient and handled instrument with both hands that inserted the port at umbilicus and left lower abdomen. First assistant was standing on the right side of the patient and handled endoscope at umbilicus. If necessary, a single instrument was added to the umbilicus port. Second assistant was sitting between the patient's leg and manipulated uterine elevator.

The ovarian cystectomy was using the monopolar coagula- 


\title{
Obstetrics \& Gynecology Science
}

\author{
Won-Kyu Choi, et al. Laparoscopic ovarian cystectomy
}

tor and putted the incision along the surface of the cyst, separated and removed gradually. Bleeding site was controled by bipolar coagulator. Resected cysts was removed through the umbilical incision site to insert the Endopouch (Ethicon EndoSurgery). If necessary, we installed a drainage through the left lower abdomen after cystectomy.

\section{2) Four ports access laparoscopic ovarian cystectomy}

One-centimeter incision in the umbilicus and $\mathrm{CO}_{2}$ filled by inserting a Verres needle. Ten-millimeter trocar was inserted. Endoscope was placed in pelvis and check the pelvis status and disease. Endoscope was consisted 10-mm-diameter, 33-cmlength, 0-degree-angle. Surgery was performed with additional trocar. Twelve-millimeter trocar was installed in the left lower abdomen, 5-mm trocar was installed in the right lower quadrant and suprapubic area.

Surgeon was standing on the left side of patient and handled instrument with both hands that inserted the port at suprapubic area and left lower abdomen. First assistant was standing on the right side of the patient and handled instrument at right lower abdomen. Second assistant was standing on the head of the patient and controled endoscope. Third assistant was sitting between the patient's leg and manipulated uterine elevator.

This method was performed in the same way as two-port laparoscopic cystectomy. Resected cysts was removed through the left lower abdomen trocar to insert the Endopouch. If necessary, we installed a drainage through the left lower abdomen after cystectomy.

\section{Statistical analysis}

SPSS ver. 17.0 (SPSS Inc., Chicago, IL, USA) was used for statistical analysis of the study results. We used the Shapiro-Wilk test in the normal distribution of the variables, Mann-Whitney $U$-test and Student's $t$-test was used for comparison of continuous variables. We use the chi-square analyses or Fischer's exact test comparison of nominal variables. Statically significant was based on the $P$-value 0.05 .

\section{Results}

\section{Characteristics of patients}

Total patients was 489. One hundred seventy-five patients underwent two-ports access laparoscopic surgery, 314 patients underwent four-ports access laparoscopic surgery. There was no statistically significant difference in average age and parity between the two-ports access laparoscopic surgery group and four-ports access laparoscopic surgery group were 30.4 and 31.4 years, 1.2 and 1.3 times. Weight between the two groups were 56.6 and $56.2 \mathrm{~kg}$, body mass index was 21.9 and $21.9 \mathrm{~kg} / \mathrm{m}^{2}$. There was no statistically significant difference 41 (23.4\%) and $78(24.3 \%)$ at a history of previous abdominal surgery (Table 1).

\section{Operative characteristics}

Bilateral cysts is whether two-ports access laparoscopic surgery is 151 unilateral surgery group (86.3\%) patients, 24 were bilateral (13.7\%) patients, four-ports access laparoscopic surgery, each group 212 (67.5\%) patients, 102 (32.5\%) are significantly more bilateral in four-ports access laparoscopic surgery were in the surgical group method $(P=0.000)$.

Histological characteristics were similar in the two groups. Endometriosis was most common in both groups, showed a mature cystic teratoma in the second. The two-ports access laparoscopic surgery group was serous ovarian cyst, four-ports access laparoscopic surgery group showed a lot of third mucinous ovarian cyst (Table 2).

\section{Results of laparoscopic surgery}

We divided groups by unilateral or bilateral and diameter of the cyst less than $6 \mathrm{~cm}$ or more than $6 \mathrm{~cm}$ in two-ports and

Table 1. Characteristics of the patients

\begin{tabular}{|lccc|}
\hline Characteristics & 2 Port $(\mathbf{n}=\mathbf{1 7 5})$ & 4 Port $(\mathbf{n}=\mathbf{3 1 4})$ & $\boldsymbol{P}$-value \\
\hline Age $(\mathrm{yr})$ & $30.4 \pm 7.6$ & $31.4 \pm 7.5$ & 0.160 \\
Parity & $1.2 \pm 0.4$ & $1.3 \pm 0.4$ & 0.296 \\
Body weight $(\mathrm{kg})$ & $56.6 \pm 8.1$ & $56.2 \pm 10.3$ & 0.673 \\
Body mass index $\left(\mathrm{kg} / \mathrm{m}^{2}\right)$ & $21.9 \pm 2.9$ & $21.9 \pm 3.8$ & 0.937 \\
Previous surgery & $41(23.4)$ & $78(24.3)$ & 0.811 \\
\hline
\end{tabular}

Values are presented as mean \pm standard deviation or number (\%). 


\title{
Obstetrics \& Gynecology Science
}

\author{
Vol. 57, No. 5, 2014
}

four-ports access laparoscopic surgery. And we investigated hemoglobin change, hospital day, adhesiolysis, transfusion, drainage tube installed, additional analgesics.

There was no significant difference in operation time for unilateral cyst excision of the cyst diameter less than $6 \mathrm{~cm}$. The operation time was 55.5 and 54.3 minutes for two-port and four-port laparoscopic surgery.

Hemoglobin change, hospital day, adhesiolysis, blood transfusion, drainage tube installed even if no significant differences. However, 41 patients (39.4\%), in four-ports access laparoscopic surgery showed significantly more used method in 50 cases $(50.5 \%)$ in this process additional analgesics administration. A unilateral cyst was $6 \mathrm{~cm}$ or more in diameter and operative time was 47 vs. 113 cases and 66.8 and 62.5 minutes respectively, they was not significantly different. Hemoglobin change, hospital day, adhesiolysis, drainage tube installed, additional analgesics, transfusion, there was no significant difference. However, additional analgesics was significantly more used 14 patients $(29.8 \%)$ in tow ports access laparoscopic surgery, 63 cases $(55.8 \%)$ in four-ports access laparoscopic surgery (Table 3).
If in bilateral ovarian cystectomy is less than the diameter of the cyst $6 \mathrm{~cm}$, was the method and technique used were 15 and 68 cases, respectively, and there was no significant difference in operative time was 58.8 to 64.6 minutes. In addition, no significant difference in hemoglobin change, hospital day, adhesiolysis, transfusion, drainage tube and additional analgesics. There was no significantly difference in case of bilateral cysts less than $6 \mathrm{~cm}$ in diameter was 9 and 34 cases, operation time was 89.9 and 81.4 minutes. Hemoglobin change, hospital day, adhesiolysis, transfusion, drainage tube installed, additional analgesics administration showed no significant difference (Table 4).

\section{Discussion}

The laparoscopic surgery in gynecology area after salpingectomy has been performed for the first time using the Shapiro and Adler pelviscope on 1973 [4], diagnostic and therapeutic purposes gradually started to be used widely. Been made since the development of complementary technologies, they present

Table 2. Characteristics of the ovarian cysts between two-port and four port access laparoscopic ovarian cystectomy

\begin{tabular}{|lccc|}
\hline Operative characteristics & 2 Port $(\mathbf{n}=\mathbf{1 7 5})$ & 4 Port $(\mathbf{n}=\mathbf{3 1 4})$ & $\mathbf{P}$-value \\
\hline Bilaterility & $24(13.7)$ & $102(32.5)$ & 0.000 \\
Pathologic findings & & & 0.081 \\
Endometrioma & $109(62.3)$ & $188(59.9)$ \\
Dermoid & $48(27.4)$ & $95(30.3)$ \\
Mucinous cyst & $7(4)$ & $17(5.4)$ \\
Serous cyst & $8(4.6)$ & $5(1.6)$ \\
Others & $3(1.7)$ & $9(2.9)$ \\
\hline
\end{tabular}

Values are presented as number (\%).

Table 3. Operative characteristics of unilateral laparoscopic ovarian cystectomy

\begin{tabular}{|c|c|c|c|c|c|c|}
\hline \multirow{2}{*}{ Outcomes } & \multicolumn{3}{|c|}{ Cyst diameter $<6 \mathrm{~cm}$} & \multicolumn{3}{|c|}{ Cyst diameter $\geq 6 \mathrm{~cm}$} \\
\hline & 2 Port $(n=104)$ & 4 Port $(n=99)$ & $P$-value & 2 Port $(n=47)$ & 4 Port $(n=113)$ & $P$-value \\
\hline Size $(\mathrm{cm})$ & $4.2 \pm 1.0$ & $4.1 \pm 1.1$ & 0.475 & $7.9 \pm 2.0$ & $8.5 \pm 2.9$ & 0.242 \\
\hline Operation time (min) & $55.5 \pm 16.3$ & $54.3 \pm 20.5$ & 0.654 & $66.8 \pm 21.8$ & $62.5 \pm 28.1$ & 0.145 \\
\hline Hemoglobin change ( $\mathrm{g} / \mathrm{dL})$ & $1.8 \pm 0.9$ & $1.6 \pm 1.0$ & 0.070 & $1.8 \pm 0.8$ & $1.6 \pm 1.0$ & 0.180 \\
\hline Hospital stay (day) & $3.4 \pm 1.0$ & $3.2 \pm 0.5$ & 0.088 & $3.3 \pm 0.6$ & $3.5 \pm 1.1$ & 0.105 \\
\hline Adhesiolysis & $50(48.1)$ & $60(60.1)$ & 0.073 & $15(31.9)$ & $42(37.2)$ & 0.527 \\
\hline Transfusion & $2(0.2)$ & $0(0.0)$ & 0.168 & $0(0.0)$ & $1(0.8)$ & 0.518 \\
\hline Hemo-vac & $17(16.3)$ & $21(21.2)$ & 0.374 & $18(38.3)$ & $42(37.2)$ & 0.893 \\
\hline Analgesics & $41(39.4)$ & $50(50.5)$ & 0.019 & $14(29.8)$ & $63(55.8)$ & 0.011 \\
\hline
\end{tabular}

Values are presented as mean \pm standard deviation or number (\%). 


\section{Obstetrics \& Gynecology Science}

Won-Kyu Choi, et al. Laparoscopic ovarian cystectomy

Table 4. Operative characteristics of bilateral laparoscopic ovarian cystectomy

\begin{tabular}{|c|c|c|c|c|c|c|}
\hline \multirow{2}{*}{ Outcomes } & \multicolumn{3}{|c|}{ Cyst diameter $<6 \mathrm{~cm}$} & \multicolumn{3}{|c|}{ Cyst diameter $\geq 6 \mathrm{~cm}$} \\
\hline & 2 Port $(n=15)$ & 4 Port $(n=68)$ & $P$-value & 2 Port $(n=9)$ & 4 Port $(n=34)$ & $P$-value \\
\hline Size $(\mathrm{cm})$ & $3.9 \pm 1.2$ & $4.0 \pm 1.1$ & 0.858 & $9.8 \pm 4.1$ & $8.2 \pm 1.8$ & 0.078 \\
\hline Operation time (min) & $58.8 \pm 14.8$ & $64.6 \pm 23.1$ & 0.356 & $89.9 \pm 51.2$ & $81.4 \pm 24.8$ & 0.482 \\
\hline Hemoglobin change (g/dL) & $1.6 \pm 0.7$ & $1.6 \pm 0.8$ & 0.954 & $1.3 \pm 0.8$ & $1.7 \pm 1.0$ & 0.227 \\
\hline Hospital stay (day) & $3.8 \pm 1.7$ & $3.2 \pm 0.8$ & 0.226 & $3.0 \pm 0.2$ & $3.3 \pm 0.6$ & 0.127 \\
\hline Adhesiolysis & $12(80)$ & $53(77.9)$ & 0.861 & $4(44.4)$ & $18(52.9)$ & 0.650 \\
\hline Transfusion & $0(0.0)$ & $1(1.4)$ & 0.637 & $0(0.0)$ & $0(0.0)$ & NS \\
\hline Hemo-vac & $3(20.0)$ & $16(23.5)$ & 0.768 & $4(44.4)$ & $14(41.2)$ & 0.860 \\
\hline Analgesics & $5(33.3)$ & $36(52.9)$ & 0.369 & $1(11.1)$ & $13(38.2)$ & 0.299 \\
\hline
\end{tabular}

Values are presented as mean \pm standard deviation or number (\%).

NS, not significant.

a new mechanism has been used in surgery for most gynecologic malignancies and benign diseases today. Laparoscopic surgery are bleeding, adhesion formation (adhesion formation), such as infection (infection) complications (complication) less after surgery than open surgery, less incision may have cosmetic effects. It has the advantage that it can shorten the hospital stay, faster recovery after surgery, the pain is less [5].

Research was continued from the past of laparoscopic surgery approach, which was to make the results of research in the direction of the best path to a minimum. It has been reported in several urological surgery and appendectomy surgery, cholecystectomy, such as single-port access laparoscopic surgery through the umbilicus [6-9]. In obstetrics area, Wheeless and Thompson [10] tried for the first time in single port access laparoscopic surgery tubal ligation. Pelosi and Pelosi [11] was an attempt to have hysterectomy and bilateral salpingo-oophorectomy on 1991, since then the single port operation was used in ovarian operation such as ovarian cystectomy, salpingectomy. It was also used for staging of the Gynecologic Cancer [12].

If the four-ports access laparoscopic surgery using 3 or 4 ports, leaving the rest of the surgical scar other than navel port. However, this advantage cannot be found almost hidden by the folds of the belly surgery marks are the single port access laparoscopic surgery using only one incision in the belly button. Umbilicus is the thinnest part where no blood vessels, muscle, nerve tissue in the abdominal wall. It is known that there is a reduction in pain after the operation, as significant effect as to maximize the effect of the cosmetic surgery through an incision in the region of umbilicus [13].

However, single port access laparoscopic surgery is using a one port. This hinders the freedom of movement of the mechanism during operation, causing a collision. In addition, the operating time may increase the operation complicated and technically difficult to occur. Therefore, it is necessary at the time of operation of the various manipulation and traction angle. However, it is difficult for the restricted manipulation and movements of the instrument when single port access laparoscopic surgery $[7,14]$. One of minimally invasive surgery to compensate for this, it is attempted two-ports access laparoscopic surgery. The advantage of this method is using the instruments previously used [15], and it is possible to switch to the four-ports access laparoscopic surgery as needed. Kim et al. [16] compared to benign ovarian cystectomy by a single port access laparoscopic surgery and two-ports and four-ports access laparoscopic surgery. It has been reported that single port access laparoscopic surgery is more bleeding and take longer operating time than two-ports and four-ports access laparoscopic surgery. But there was no significant difference in operative time compared to two-ports access laparoscopic surgery and four-ports access laparoscopic surgery.

This study subdivided and analyzed by the size of cyst less than $6 \mathrm{~cm}$ or above $6 \mathrm{~cm}$. Unilateral cyst diameter less than $6 \mathrm{~cm}$, the operative time was 55.5 and 54.3 minutes in twoports access laparoscopic surgery and four-ports access laparoscopic surgery. More than $6 \mathrm{~cm}$, there was no significant difference between two-ports access laparoscopic surgery and four-ports access laparoscopic surgery to 66.8 and 62.5 minutes, respectively. Bilateral cyst diameter less than $6 \mathrm{~cm}$, the operative time was 58.8 and 64.6 minutes in two-ports access laparoscopic surgery and four-ports access laparoscopic surgery. More than $6 \mathrm{~cm}$, there was no significant difference between two-ports access laparoscopic surgery and four-ports 


\title{
Obstetrics \& Gynecology Science
}

\author{
Vol. 57, No. 5, 2014
}

access laparoscopic surgery to 89.9 and 81.4 minutes, respectively. In both cases, the cyst is less than $6 \mathrm{~cm}$ and above than $6 \mathrm{~cm}$ in diameter, there were no differences in perioperative hemoglobin change, hospital day, blood transfusion, drainage tube installed between two-ports access laparoscopic surgery and four-ports access laparoscopic surgery. In addition, even the adhesiolysis, which may affect the operation time was not significantly different on both groups.

However, in both cases showed unilateral cyststectomy at less $6 \mathrm{~cm}$ and $6 \mathrm{~cm}$ or more, significantly more than in fourports access laparoscopic surgery to two-ports access laparoscopic surgery of additional painkillers. And that can affect the surgery pain between the two groups were not significantly different whether the installation of the drain tube. Four-ports access laparoscopic surgery was installed in the 12-mm port in the left lower abdomen to remove the cyst, it is estimated that an increase in the pain caused by the cyst removed using twoports access laparoscopic surgery umbilical port, but the cause of additional pain medication is administered. Therefore be concluded that two-ports access laparoscopic surgery is less painful compared to four-ports access laparoscopic surgery, is considered as a method recommended for patients after surgery, you want to minimize the hurt.

In addition to a variety of possible operations to reduce the conflict between ovarian mechanism when compared with laparoscopic surgery, with benefits going to see anything useful in surgical adhesions, or ovarian cyst the size of a large. However, there were limitations such as appropriate selection of the control group and variable control and retrospective studies. Therefore, a prospective study to investigate the usefulness and safety of two-ports access laparoscopic surgery for cysts, and require the comparative study of two-ports access laparoscopic surgery and four-ports access laparoscopic surgery is also considered necessary.

\section{Conflict of interest}

No potential conflict of interest relevant to this article was reported.

\section{References}

1. Hilger WS, Magrina JF, Magtibay PM. Laparoscopic management of the adnexal mass. Clin Obstet Gynecol 2006;49:535-48.

2. Eltabbakh GH, Charboneau AM, Eltabbakh NG. Laparoscopic surgery for large benign ovarian cysts. Gynecol Oncol 2008;108:72-6.

3. Capar M, Balci O, Acar A, Colakoglu MC. Management of ovarian cysts by laparoscopic extracorporeal approach using single ancillary trocar. Taiwan J Obstet Gynecol 2009;48:380-4.

4. Shapiro HI, Adler DH. Excision of an ectopic pregnancy through the laparoscope. Am J Obstet Gynecol 1973;117:290-1.

5. Lee NJ, Kim J, Lee SH, Choi WM, Lee SS, Kwon YI, et al. A clinical study on 1594 cases of operative and diagnostic laparoscopy. Korean J Obstet Gynecol 2003;46:2189-96.

6. Podolsky ER, Rottman SJ, Poblete H, King SA, Curcillo PG. Single port access (SPA) cholecystectomy: a completely transumbilical approach. J Laparoendosc Adv Surg Tech A 2009;19:219-22.

7. Canes D, Desai MM, Aron M, Haber GP, Goel RK, Stein RJ, et al. Transumbilical single-port surgery: evolution and current status. Eur Urol 2008;54:1020-9.

8. Kommu SS, Kaouk JH, Rane A. Laparo-endoscopic single-site surgery: preliminary advances in renal surgery. BJU Int 2009;103:1034-7.

9. Canes D, Berger A, Aron M, Brandina R, Goldfarb DA, Shoskes D, et al. Laparo-endoscopic single site (LESS) versus standard laparoscopic left donor nephrectomy: matched-pair comparison. Eur Urol 2010;57:95-101.

10. Wheeless CR Jr, Thompson BH. Laparoscopic sterilization: review of 3600 cases. Obstet Gynecol 1973;42:751-8.

11. Pelosi MA, Pelosi MA 3rd. Laparoscopic hysterectomy with bilateral salpingo-oophorectomy using a single umbilical puncture. N J Med 1991;88:721-6.

12. Fader AN, Rojas-Espaillat L, Ibeanu O, Grumbine FC, Escobar PF. Laparoendoscopic single-site surgery (LESS) in gynecology: a multi-institutional evaluation. Am J Obstet Gynecol 2010;203:501.e1-6.

13. Kim YW, Park BJ, Ro DY, Kim TE. Single-port laparoscopic myomectomy using a new single-port transumbilical morcellation system: initial clinical study. J Minim Invasive Gynecol 2010;17:587-92.

14. Kim TJ, Lee YY, Kim MJ, Kim CJ, Kang H, Choi CH, et al. Single port access laparoscopic adnexal surgery. J Minim Invasive Gynecol 2009;16:612-5. 


\section{Obstetrics \& Gynecology Science}

Won-Kyu Choi, et al. Laparoscopic ovarian cystectomy

15. Paek J, Nam EJ, Kim YT, Kim SW. Overcoming technical difficulties with single-port access laparoscopic surgery in gynecology: using conventional laparoscopic instruments. J Laparoendosc Adv Surg Tech A 2011;21:137-41.
16. Kim ML, Song T, Seong SJ, Yoon BS, Joo WD, Jung YW, et al. Comparison of single-port, two-port and four-port laparoscopic surgery for cyst enucleation in benign ovarian cysts. Gynecol Obstet Invest 2013;76:57-63. 